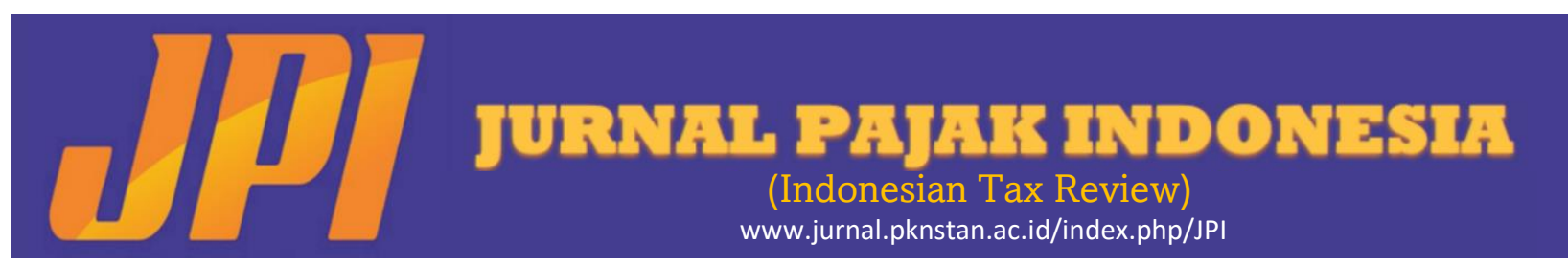

\title{
MENELAAH RENCANA KENAIKAN TARIF PPN BERDASARKAN BUKTI EMPIRIS SERTA DAMPAKNYA SECARA MAKRO EKONOMI
}

\author{
Nur Farida Liyana \\ Politeknik Keuangan Negara STAN \\ Alamat Korespondensi: faridaliyana@pknstan.ac.id
}

\section{INFORMASI ARTIKEL}

Diterima Pertama

[30102021]

Dinyatakan Diterima

[12112021]

KATA KUNCI:

PPN, tarif, PDB, pertumbuhan ekonomi, konsumsi, inflasi, rasio utang

KLASIFIKASI JEL:

E71

\section{ABSTRAK}

The plan to increase the VAT rate to 11 percent by 2022 has caused anxiety in the community. In the midst of the COVID-19 pandemic and the economy has not yet recovered, the idea of rising commodity prices which is then accompanied by inflation is certainly disturbing not only for entrepreneurs but also for ordinary people. For this reason, in this paper, we carry out empirical evidence regarding the relationship between VAT and economic growth and the national saving rate in Indonesia. Then we will see the impact of the planned increase in the VAT rate on a macroeconomic basis by comparing the experience of Japan which has increased its VAT rate by 3 (three)) times over the last 15 years. It was concluded that what the government was doing was on the right track because empirical evidence by performing OLS regression said that there was a significant positive relationship between VAT and GDP and national saving. So that what the government is doing is on the right track, raising the VAT rate is expected to encourage economic growth and attract foreign financing to Indonesia. However, it is necessary to first analyze the impact of the increase in the VAT rate on the macro economy. Based on lessons learned from Japan, it turns out that the increase in the VAT rate is not able to increase consumption and economic growth, but instead raises inflation. This needs special attention for the Government of Indonesia so that efforts are needed to mitigate these things.

Rencana kenaikan tarif PPN menjadi 11 persen pada tahun 2022 telah menimbulkan kegelisahan di masyarakat. Ditengah pandemic covid-19 dan ekonomi yang belum pulih, bayangan perihal harga komoditas naik yang kemudian diiringi dengan inflasi tentunya meresahkan tidak hanya bagi pengusaha namun juga masyarakat biasa. Untuk itu di dalam tulisan ini dilakukan pembuktian empiris dengan menggunakan regresi OLS untuk menguji hubungan antara PPN dengan pertumbuhan ekonomi serta tingkat tabungan nasional di Indonesia. Kemudian akan dianalisis dampak rencana kenaikan tarif PPN tersebut secara makro ekonomi dengan melakukan perbandingan pengalaman Jepang yang pernah menaikkan tarif PPN nya sebanyak 3 (tiga) kali selama 15 tahun terakhir. Diperoleh kesimpulan bahwa apa yang dilakukan pemerintah sudah pada jalur yang benar karena bukti empiris menyatakan hubungan positif signifikan antara PPN dan PDB serta tabungan nasional. Sehingga dengan menaikkan tarif PPN diharapkan akan mendorong pertumbuhan ekonomi dan menarik pembiayan luar negeri ke Indonesia. Namun demikian, perlu dianalisis terlebih dahulu dampak kenaikan tarif PPN terhadap ekonomi makro. Berdasarkan pembelajaran dari Jepang, ternyata kenaikan tarif PPN tidak mampu menaikkan konsumsi dan pertumbuhan ekonomi namun justru menaikkan inflasi. Hal ini perlu menjadi perhatian khusus bagi Pemerintah Indinesia sehingga perlu usaha untuk memitigasi hal-hal tersebut. 


\section{PENDAHULUAN}

Pajak merupakan tulang punggung pembangunan negara. Hal ini tidak hanya berlaku bagi negara berkembang seperti Indonesia namun juga berlaku di seluruh dunia tidak terkecuali negara maju. Salah satu jenis pajak yang saat ini sedang menjadi hot topic di Indonesia adalah Pajak Pertambahan Nilai (PPN). Dimana dalam Rancangan UU Harmonisasi Peraturan Perpajakan pada Pasal 7 disebutkan bahwasannya Tarif PPN akan berubah dari $10 \%$ menjadi 11\% per 1 April 2022 dan menjadi 12\% paling lambar 1 Januari 2025.

Dengan adanya perubahan tersebut tentunya akan mempengaruhi perekonomian Indonesia. Beberapa penelitian telah menyimpulkan bahwa ada hubungan antara PPN dengan pertumbuhan ekonomi. Seperti yang diungkapkan oleh Ebrill et al. (2001) yang menemukan bahwa pengumpulan penerimaan PPN berbanding lurus dengan pendapatan per kapita dan tingkat melek huruf. Hal ini berarti seiring pendapatan per kapita naik dan tingkat melek huruf yang tinggi maka penerimaan PPN juga akan semakin tinggi. Pendapat ini juga diperkuat oleh Wijaya (2013) yang menyimpulkan bahwa secara parsial pertumbuhan ekonomi memiliki pengaruh yang positif dan signifikan terhadap penerimaan PPN di Bali pada April 2010 s.d September 2012.

Sehingga dengan adanya kenaikan tarif PPN tersebut diharapkan akan memberikan dampak yang signifikan terhadap penerimaan pajak. Hal ini juga didukung dengan pertumbuhan kelompok pendapatan menengah yang terus naik dari tahun ke tahun sehingga akan meningkatkan nilai konsumsi dan meningkatkan penerimaan pajak dari PPN (Kemenkeu, 2021). Selain itu, kondisi ini selaras dengan model pertumbuhan ekonomi yang dikemukakan oleh Domar (1946) yang menyatakan bahwa pertumbuhan ekonomi didorong oleh dua variabel yaitu produktivitas modal dan tingkat tabungan nasional. Sehingga semakin tinggi tingkat tabungan nasional menghasilkan investasi yang tinggi yang akan mengakibatkan produksi dan konsumsi nasional juga akan semakin tinggi yang berarti bahwa PPN juga akan semakin tinggi.

Untuk itulah dalam penelitian ini kita akan melakukan studi empiris terhadap hubungan antara PPN dengan pertumbuhan ekonomi serta tingkat tabungan nasional di Indonesia. Studi empiris ini dilakukan untuk mengetahui apakah keputusan pemerintah dengan menaikkan PPN sudah tepat atau belum. Kemudian kita akan melihat motif pemerintah memilih kebijakan menaikkan tarif PPN dan melihat dampak rencana kenaikan tarif PPN tersebut secara makro ekonomi dengan melihat perbandingan pengalaman Jepang yang pernah menaikkan tarif PPN nya sebanyak 3 (tiga) kali selama 15 tahun terakhir.

Manfaat dari penelitian ini tentunya untuk menambah referensi penelitian terkait dampak kenaikan tarif PPN serta mengevaluasi kebijakan pemerintah tersebut. Selain itu juga dapat memberikan masukan kepada pemerintah terkait apa saja yang harus dilakukan untuk memitigasi resiko makro ekonomi akibat dampak kenaikan tarif PPN setelah belajar dari pengalaman Jepang.

\section{LITERATUR REVIEW}

\subsection{Teori PPN}

Di banyak negara PPN didefinisikan sebagai Value Added Taxes atau Consumption Tax. Berdasarkan Sukardji (2009), pajak konsumsi adalah pajak yang dikenakan atas pengeluaran yang ditujukan untuk konsumsi. Due \& Friedlaender (1984) membedakan pajak konsumsi menurut pendekatannya yaitu pendekatan langsung dan tidak langsung. PPN termasuk pajak tidak langsung. PPN dijadikan sebagai suatu pilihan jenis pajak oleh banyak negara karena memiliki beberapa karakteristik positif seperti: 1) Pajak atas konsumsi, 2) Pajak tidak langsung, 3) Netral, dan 4) Non cumulative (Terra, 1988).

Menurut Sukardji (2009) kelebihan PPN adalah sebagai berikut: 1) Mencegah pajak berganda, 2) Netral, 3) Membantu likuiditas perusahaan, 4) PPN sebagai money maker. Sementara itu kelemahan PPN adalah sebagai berikut: 1) Biaya administrasi tinggi, 2) Menimbulkan dampak regresif, 3) Rawan penyelundupan pajak, dan 4) Menuntut tingkat pengawasan yang lebih cermat.

\subsection{Teori Makroekonomi}

Ekonomi Makro merupakan cabang ilmu ekonomi yang mempelajari masalah-masalah ekonomi secara global dan menyeluruh. Mankiw (2007) yang menyebutkan bahwa ada beberapa hal yang dipelajari dalam ekonomi makro diantaranya Produk Domestik Bruto (PDB), tingkat inflasi, dan tingkat pengangguran. Lebih lanjut Mankiw (2007) mengemukakan bahwa ada 3 (tiga) alasan mengapa harus belajar ekonomi makro yaitu: 1) Ekonomi makro mempengaruhi kesejahteraan masyarakat, 2) Ekonomi makro mempengaruhi kesejahteraan Anda, dan 3) Ekonomi makro mempengaruhi politik.

PDB dan pertumbuhan ekonomi merupakan salah satu aspek ekonomi makro yang terpengaruh oleh konsumsi, investasi, pengeluaran pemerintah, dan nett-export (Mankiw, 2007). Pertumbuhan ekonomi sangat penting untuk diperhatikan karena dengan ekonomi bertumbuh maka standar hidup naik dan kemiskinan menurun. Model pertumbuhan Solow menunjukkan bahwa standar hidup masyarakat bergantung positif pada tingkat tabungan dan negative pada pertumbuhan penduduk. Hal ini berarti semakin tinggi tingkat tabungan nasional semakin bagus standar hidup masyarakatnya dan semakin tinggi pertumbuhan penduduk semalin rendah standar hidup masyarakatnya. Lebih lanjut disebutkan 
bahwa dampak penurunan tabungan nasional menyebabkan suku bunga naik dan investasi turun.

\subsection{Hubungan PPN dengan Pertumbuhan Ekonomi}

Banyak makalah dan penelitian yang menyatakan bahwa hubungan PPN dengan pertumbuhan ekonomi adalah positif signifikan. Hal ini seperti diuraikan oleh Anojan (2015) yang menyatakan bahwa pajak konsumsi atau PPN memiliki korelasi positif dengan pertumbuhan ekonomi dalam hal ini PDB. Demikian hal nya yang dikemukakan oleh Wijaya (2013) yang menyatakan bahwa ada hubungan positif antara pertumbuhan ekonomi dengan penerimaan PPN. Sehingga PPN dan pertumbuhan ekonomi bisa saling mempengaruhi.

Namun demikian, Miki (2011) menemukan bahwa kenaikan tarif pajak dalam short term justru akan membuat pertumbuhan ekonomi menurun. Sehingga terjadi perdebatan terkait dengan pengaruh PPN terhadap pertumbuhan ekonomi. Hal ini diperkuat oleh Hakim (2016) yang menemukan bahwa PPN memiliki dampak negative pada negara berkembang namun memiliki dampak yang konstruktif di negara maju.

Sehingga dampak dari PPN terhadap pertumbuhan ekonomi masih menjadi perdebatan. Sehingga dalam penelitian ini akan kita lakukan studi empiris dengan data di Indonesia.

\subsection{Hubungan PPN dengan Tingkat Tabungan Nasional}

Dahri, et.al (2019) menemukan bahwa PPN memiliki dampak positif signifikan dengan tabungan nasional baik di Jepang maupun di Pakistan. Hal ini didukung oleh Sthanumoorthy (2006) dan Alm \& ElGanainy (2012). Aini \& setyari (2019) mengemukakan bahwa tabungan nasional meningkatkan investasi asing sehingga akan berdampak positif pada pembiayaan nasional.

Dengan adanya hubungan positif antara PPN dan tingkat tabungan nasional, tentunya memberikan harapan yang baik dengan kenaikan tarif PPN akan menaikkan tabungan nasional dan investasi luar negeri juga akan semakin tinggi.

\subsection{Sejarah PPN Jepang}

Jepang merupakan salah satu negara maju di Asia. PPN atau di Jepang disebut dengan Consumption Tax diperkenalkan di Jepang pada tahun 1989 dengan tarif 3\% kemudian naik menjadi 5\% pada tahun 1997. Pada tahun 2014 Pemerintah Jepang Kembali menaikkan PPN menjadi 8\% dan pada tahun 2019 menjadi $10 \%$. Kontribusi penerimaan PPN Jepang terhadap PDB adalah 6,445\% pada tahun 2015 (Dahri, et.al., 2019).

\subsection{Sejarah PPN di Indonesia}

Sementara itu di Indonesia, PPN diperkenalkan pada tahun 1947 dengan nama Pajak Pembangunan I. Berdasarkan Maulida (2018) kemudian pada tahun 1950 berlaku Pajak Peredaran dengan tarif 2,5\%. Kemudian cikal bakal PPN modern baru dimulai pada tahun 1951. Berdasarkan Undang-Undang Darurat Nomor 19 Tahun 1951 sttd Undang-Undang Nomor 35 Tahun 1953 dengan nama Pajak Penjualan, PPN saat itu dinamakan dengan Pajak Penjualan (Sukardji, 2009). Selama kurang lebih tiga puluh tahun Pajak Penjualan telah memberikan kontribusi yang sangat penting atas konsumsi di Indonesia. Dengan adanya reformasi perpajakan pada tahun 1983, lahirlah Undang-Undang Nomor 8 Tahun 1983 yang menjadi dasar pemungutan PPN dengan tarif $10 \%$.

Berdasarkan Sukardji (2009), karakteristik PPN di Indonesia adalah sebagai berikut:

1. PPN merupakan pajak tidak langsung

2. Pajak Objektif

3. Multi Stage Tax

4. PPN terutang untuk dibayar ke kas negara dihitung menggunakan indirect subtraction method/credit method/invoice method

5. PPN merupakan pajak atas konsumsi umum dalam negeri

6. PPN bersifat netral

7. Tidak menimbulkan dampak pengenaan pajak berganda

\section{METODE PENELITIAN}

Tujuan dari penelitian ini adalah untuk mengamati secara statistik dampak kausal PPN terhadap $\mathrm{PDB} /$ pertumbuhan ekonomi dan tingkat tabungan nasional untuk melihat apakah kebijakan pemerintah menaikkan tarif PPN sudah merupakan keputusan yang tepat. Kemudian setelah itu akan dilakukan studi komparatif dengan membandingkan kondisi Jepang yang telah melakukan tiga kali kenaikan tarif PPN untuk melihat dampak kebijakan kenaikan tarif PPN tersebut secara makro ekonomi.

Untuk melihat dampak kausal PPN terhadap PDB dan tabungan nasional maka akan dibangun dua model. Model yang dibangun dalam penelitian ini adalah sebagai berikut:

$$
\begin{aligned}
& G D P_{g r}=\beta_{0}+\beta_{1} \text { Tax }+\varepsilon \ldots \ldots \ldots \ldots \ldots . . .(1) \\
& \text { Gr_Saving }=\beta_{0}+\beta_{1} \text { Tax }+\varepsilon \ldots \ldots \ldots \ldots \ldots . . .(2) \\
& \begin{array}{ll}
\text { Dimana: } & \\
\text { GDP } & =\text { PDB Harga Berlaku (Triliun Rupiah) } \\
\text { Gr_Saving } & =\text { Tingkat Tabungan Nasional (Triliun } \\
\text { piah) } & \\
\text { Tax } & =\text { Penerimaan PPN (Triliun Rupiah) }
\end{array}
\end{aligned}
$$
Rupiah)

Data yang akan digunakan adalah data sekunder dimana GDP_gr berasal dari data Kementerian Keuangan RI (Direktorat Jenderal Anggaran)

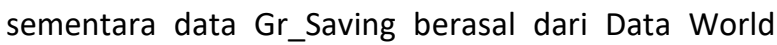


Bank dan data Tax berasal dari Data Direktorat Jenderal Pajak dari tahun 2002 sampai dengan tahun 2019.

Dengan menggunakan Regresi OLS dengan bantuan aplikasi SPSS kita akan mengestimasi model yang telah kita bangun dan akan melihat bagaimana hubungan antara PPN dengan pertumbuhan ekonomi dan tingkat tabungan nasional. Hipotesis awal yang dibangun adalah PPN akan berpengaruh positif signifikan terhadap PDB dan tabungan nasional. Jika hipotesis tersebut terpenuhi maka kebijakan pemerintah dapat dianggap tidak salah langkah.

Kemudian studi komparatif dengan Jepang akan menggunakan data-data berkaitan dengan Inflasi, Konsumsi, Pertumbuhan Ekonomi dari World Bank, IMF serta data dari Kementerian Keuangan baik Jepang maupun Indonesia. Dari studi ini akan diambil pelajaran dari pengalaman Jepang sehingga bisa dilakukan antisipasi oleh Pemerintah Indonesia jika ada dampak negative akibat kenaikan tarif PPN ini.

\section{HASIL PENELITIAN}

\subsection{Hubungan PPN dengan Pertumbuhan Ekonomi}

Setelah kita melakukan running regresi dengan metode OLS maka dihasilkan hasil sebagai berikut:

$$
G D P_{g r}=-310.117+28.5 \operatorname{Tax}+\varepsilon
$$

Tabel 1: Resume Model 1

\begin{tabular}{llcl}
\hline \hline & \multicolumn{4}{l}{ Independent var: PPN } \\
\hline PDB & $\begin{array}{l}\text { Adj. } \mathbf{R} \\
\text { Square }\end{array}$ & $\beta_{1}$ & Sig. \\
& 0.983 & 28.5 & 0.000 \\
\hline
\end{tabular}

Sumber: Data Diolah

Dari Tabel 1 dapat dilihat bahwasanya antara PPN dan PDB memiliki hubungan positif yang signifikan. Hal ini bisa dilihat dari nilai signifikansi kurang dari 0.05. Sementara itu nilai Adjusted $R$ Square nya sebesar 0.983 menyatakan bahwa model telah dapat merepresentasikan data sebesar $98.3 \%$ yang berarti bahwa model fit terhadap data. Sementara itu nilai kontanta PPN sebesar 28.5 mengindikasikan bahwa jika PPN meningkat Rp 1 Triliun maka PDB akan naik sebesar Rp 28.5 Triliun.

Hal ini sesuai dengan yang disimpulkan oleh Anojan (2015) dan Dahri et.al (2019) dimana PPN memang memberikan dampak positif signifikan terhadap pertumbuhan ekonomi dalam hal ini PDB. Sehingga dapat disimpulkan bahwa dengan adanya kenaikan tarif PPN akan meningkatkan nilai PDB sehingga pertumbuhan ekonomi juga akan meningkat. Sehingga kebijakan kenaikan tarif PPN untuk meningkatkan perekonomian sudah pada jalur yang benar.

\subsection{Hubungan PPN dengan Tingkat Tabungan Nasional}

Sementara itu berkaitan dengan hubungan antara PPN dengan tingkat tabungan nasional adalah sebagai berikut:

$$
G r_{\text {Saving }}=-293.6+9.3 \operatorname{Tax}+\varepsilon
$$

Tabel 2: Resume Model 2

\begin{tabular}{llcl}
\hline \hline & \multicolumn{4}{l}{ Independent var: PPN } \\
\hline Tingkat & \multicolumn{1}{l}{ Adj. R } & $\beta_{1}$ & Sig. \\
Tabungan & Square & & \\
\cline { 2 - 4 } Nasional & $\mathbf{0 . 9 8 1}$ & 9.3 & 0.000 \\
\hline
\end{tabular}

Sumber: Data Diolah

Berdasarkan Tabel 2 dapat dilihat bahwa PPN berpengaruh positif signifikan terhadap tabungan nasional. Hal ini dapat dilihat dari nilai signifikansi kurang dari 0.05. Sementara itu adj. R Square 98.1\% menyatakan bahwa model sudah memenuhi goodness of fitted yang berarti bahwa model sudah dapat mewakili data. Selanjutnya, konstanta $\beta_{1} 9.3$ berarti bahwa setiap PPN naik sebesar Rp 1 Triliun maka tabungan nasional akan naik sebesar Rp 9.3 Triliun.

Dengan adanya hubungan positif antara PPN dan tabungan nasional maka investasi luar negeri pun akan terdampak. Hal ini sesuai dengan yang ditemukan oleh Aini \& setyari (2019), bahwa ada hubungan positif signifikan antara tabungan nasional dengan investasi asing langsung di Indonesia. Hal ini berarti bahwa dengan naiknya tabungan nasional maka investasi asing langsung akan naik yang berarti pembiayaan pembangunan dapat bertambah. Sehingga dengan kenaikan tarif PPN maka bisa diestimasi bahwa penerimaan PPN akan naik yang menyebabkan tabungan nasional naik dan akan berdampak pada investasi asing langsung pun akan ikut naik. Dapat disimpulkan bahwa pemerintah tidak salah langkah untuk menaikkan tarif PPN sebagai salah satu pendongkrak pembiayaan.

\subsection{Motif Pemerintah dan Dampak Kenaikan Tarif PPN Dilihat dari Makro Ekonomi (Belajar dari Jepang)}

Jepang merupakan salah satu negara maju yang tercatat telah beberapa kali menaikkan tarif PPN atau disebut Consumption Tax. Tercatat pada tahun 1997, 2014 dan 2019 perlahan Pemerintah Jepang menaikkan PPN dari 3\% ke 5\% kemudian menjadi $8 \%$ dan terakhir $10 \%$. Alasan pemerintah Jepang menaikkan tarif salah satunya adalah posisi utang negara yang mencapai lebih dari tiga kali lipat dalam beberapa decade terakhir bahkan mencapai 200 persen PDB Jepang (Keen, et.al, 2011). Hal ini dikarenakan population aging (penduduk tua yang lebih besar dari penduduk usia produktif) sehingga 
Jepang dihadapkan kepada masalah pembiayaan social security.

Sementara itu, apa yang terjadi di Indonesia juga dilatarbelakangi oleh motif pemerintah untuk mengembalikan kesehatan fiscal nasional. Seperti kita ketahui bersama pandemic covid 19 telah membuat Pemerintah Indonesia harus mengeluarkan dana besar untuk berbagai hal mulai dari insentif ekonomi sampai dengan pengadaan vaksin. Oleh karena itu, pada tahun 2020 utang Pemerintah Indonesia mencapai Rp $6000 \mathrm{~T}$ dimana angka tersebut mencapai lebih dari 40\% dari PDB nasional (Kemenkeu, 2020). Untuk itu, pemerintah perlu untuk membuat kebijakan agar kesehatan fiscal dapat tercapai.

Alasan Pemerintah Jepang berikutnya adalah dikarenakan tarif 5\% yang berlaku mulai tahun 1997 terlalu rendah jika dibandingkan dengan tarif PPN di negara lain. Bahkan di Eropa rata-rata tarif PPN mencapai $20 \%$. Hal ini juga yang menjadi alasan Pemerintah Indonesia menaikkan tarif PPN. Seperti terlihat di Tabel 3 (terlampir), jika dibandingkan dengan negara lain, rata-rata tarif PPN dari 74 negara tersebut adalah $14 \%$ sementara tarif di Indonesia masih $10 \%$.

Berkaitan dengan pelaksanaan kenaikan tarif di Jepang, Pemerintah Jepang mengikuti 4 (empat) prinsip sebagai berikut (Keen, et.al, 2011):

1. Waktu harus tepat

Kenaikan PPN dilakukan secepatnya tanpa menunggu waktu. Hal ini dimaksudkan untuk memperkuat ketahanan fiscal.

2. Dilakukan secara bertahap

Untuk mengurangi dampak negative pada pertumbuhan ekonomi, maka kenaikan tarif dilakukan secara bertahap. Bahkan pengumuman kenaikan tarif juga dilakukan jauh-jauh hari untuk menstimulasi belanja masyarakat di awal waktu.

3. Berikan jangka waktu

Pelaksanaan tarif tertentu harus ada jangka waktu yang lumayan lama sehingga dapat dilakukan evaluasi secara menyeluruh.

4. Sederhanakan desain

Kenaikan tarif harus sesederhana mungkin untuk menghindari beban yang lebih tinggi untuk masyarakat berpendapatan rendah.

Dari keempat prinsip tersebut sepertinya sudah diikuti oleh Pemerintah Indonesia dalam rangka rencana menaikkan tarif PPN yang akan berlaku pada April 2022. Sehingga yang penting untuk didiskusikan bersama adalah bagaimana dampak kenaikan PPN ini, apakah memang sudah sesuai denga $n$ motif atau tujuan pemerintah? Kita akan bahas bersama dengan belajar dari pengalaman Jepang dua kali melakukan kenaikan tarif yaitu di tahun 1997 dan 2014.

Tujuan utama pemerintah Jepang dengan menaikkan tarif PPN adalah mengatasi permasalahan debt to GDP ratio (rasio utang terhadap PDB) yang mencapai $200 \%$. Sehingga harapannya adalah dengan menaikkan tarif PPN dimana tarif PPN Jepang saat itu masih lebih rendah dari negara lain, rasio utang Pemerintah Jepang bisa turun sekitar 150\% dari PDB. Namun kenyataannya adalah selama 6 tahun setelah kenaikan PPN di tahun 2014, memang rasio utang sempat turun dari $235.8 \%$ menjadi $231.3 \%$ pada tahun 2015. Kemudian rasio ini naik menjadi $236.4 \%$ pada tahun 2016 lalu turun lagi menjadi 234.5\% dan kemudian naik terus sampai menjadi $266.2 \%$ pada tahun 2020. Dari sini kita lihat bahwa harapan pemerintah Jepang untuk menstabilkan rasio utang menjadi $150 \%$ belum tercapai. Hal ini juga terjadi ketika Pemerintah Jepang menaikkan tarif PPN pada tahun 1997. Bahkan rasio utang Pemerintah Jepang tidak pernah turun dari sekitar 72\% pada tahun 1997 tersebut sampai menyentuh angka $200 \%$ pada tahun 2011.

Dari pengalaman Jepang ini, jika tujuan utama Pemerintah Indonesia adalah menurunkan rasio utang maka belum tentu akan berhasil, namun demikian dengan melihat Gambar 1 (terlampir), dapat dilihat angka rasio utang Indonesia masih di angka aman yaitu $40 \%$ pada tahun 2020 , sementara batas aman rasio utang berdasarkan UU Keuangan Negara No. 17 tahun 2003 adalah sebesar 60\%. Apalagi kondisi perekonomian Indonesia yang berbeda dengan kondisi pemerintah Jepang. Jepang mengalami population aging sejak lebih dari 20 tahun yang lalu sehingga pengeluaran pemerintah lebih banyak diperuntukkan untuk social security. Sementara itu, Indonesia masih dalam tahap bonus demografi sampai dengan 2045 dimana ada kenaikan yang signifikan untuk golongan menengah ke atas. Ditambah lagi belanja pemerintah paling besar masih didominasi oleh belanja untuk pelayanan umum dan ekonomi sementara untuk perlingdungan sosial hanya $13 \%$ saja dari total belanja nasional (APBN, 2020). Dengan demikian, apa yang terjadi di Jepang setelah kenaikan tarif PPN belum tentu terjadi di Indonesia.

Berikutnya adalah dampak kenaikan tarif PPN secara makro ekonomi yang akan dilihat dari konsumsi, pertumbuhan ekonomi, dan inflasi. Banyak teori menyebutkan bahwa dampak kenaikan PPN dalam jangka pendek adalah menaikkan konsumsi. Namun hal ini tidak berlaku bagi Jepang, seperti dijelaskan Syed et.al (2009) menyebutkan bahwa pada kenaikan PPN di 1997 justru Jepang mengalami resesi setahun setelahnya, dimana justru selama dua tahun berturut-turut pertumbuhan ekonomi Jepang mengalami minus. (lihat Gambar 2 pada lampiran). Namun, pada tahun 2014 justru sebalinya, pertumbuhan ekonomi Jepang naik setelah tarif PPN kembali dinaikkan dengan angka 0.3\% pada 2014 menjadi $1.56 \%$ pada tahun 2015 meskipun pada tahun 2016 angka ini kembali turun. (Gambar 2).

Lalu bagaimana dengan nasib Indonesia?, jika berkaca dengan negara lain selain Jepang, masih ada harapan. Seperti yang terjadi pada Denmark, Italia dan Swedia yang juga pernah menaikkan tarif PPN secara 
bertahap mengalami kenaikan pertumbuhan ekonomi lebih dari 2,5\% selama kurang lebih dua decade (Keen, et.al., 2011). Kita berharap bersama Indonesia akan mengikuti jejak Denmark (1967-1979), Swedia (19701977) dan Italia (1976-1983) yang berhasil menjaga pertumbuhan ekonomi lebih dari $2.5 \%$ pada saat kenaikan tarif PPN.

Berkaitan dengan inflasi Mody \&Ohnsorge (2007) menyimpulkan bahwa kenaikan tarif PPN 1\% akan menaikkan harga antara $0.26 \%$ s.d $0.42 \%$. Hal ini berarti kenaikan tarif PPN akan memicu kenaikan inflasi. Jika kita bandingkan untuk Jepang, memang akan menguntungkan dimana negara ini mengalami deflasi selama bertahun-tahun, namun mari kita lihat data pada Gambar 4 (terlampir). Berdasarkan Gambar 3 dapat kita lihat bahwa kenaikan PPN pada 1997 dan 2007 dalam waktu dekat dapat menaikkan inflasi di Jepang. Sementara itu jika dilihat dari sisi makro ekonomi, Hong (2019) menyatakan bahwa inflasi berdampak negative terhadap pertumbuhan ekonomi. Hal ini perlu diwaspadai oleh pemerintah Indonesia untuk dapat menekan angka inflasi ditengah rencana menaikkan tarif PPN. Seperti yang diungkapkan oleh Tait(1988) dimana menyebutkan bahwa 22 dari 35 negara berhasil menekan dampak pengenalan PPN terhadap harga dan tidak begitu berpengaruh pada perubahan inflasi. Hal ini diakibatkan dengan cara mengombinasikan reformasi pajak yang komprehensif atau kebijakan untuk mengontrol harga. Seperti kita ketahui saat ini Direktorat Jenderal Pajak sedang melakukan reformasi perpajakan jilid ke 3 . Bersamaan dengan kenaikan tarif PPN tahun 2022 juga diiringi dengan perubahan tarif dan penambahan pajak progresif pada Pajak Penghasilan. Semoga dengan kebijakan ini dampak inflasi akibat kenaikan PPN tidak terlalu signifikan mengurangi pertumbuhan ekonomi.

\section{KESIMPULAN DAN SARAN}

Kesimpulan yang dapat diambil dari paper ini adalah sebagai berikut:

1. Motif Pemerintah Indonesia menaikkan tarif PPN utamanya adalah berkaitan dengan ketahanan ekonomi Indonesia.

2. Secara empiris kebijakan pemerintah ini sudahlah tepat karena terdapat hubungan positif antara PPN dengan PDB dan Tabungan Nasional. Dimana kenaikan PPN Rp 1 T dapat meningkatkan PDB Rp 28.5 Triliun. Sementara itu, setiap PPN naik sebesar Rp 1 Triliun maka tabungan nasional akan naik sebesar Rp 9.3 Triliun dimana semakin tinggi tabungan nasional akan menaikkan pula investasi luar negeri ke Indonesia.

3. Berdasarkan dampak kenaikan tarif PPN terhadap kondisi makro ekonomi dengan membandingkan kondisi Jepang yang telah melakukan tiga kali kenaikan tarif dalam kurun waktu 15 tahun terakhir diperoleh hal-hal sebagai berikut:

a. Secara teori, kenaikan tarif dapat meningkatkan konsumsi lalu akan menaikkan pertumbuhan ekonomi. Namun di Jepang, dikarenakan konsumsi lebih banyak dilakukan untuk social security sehingga kenaikan tarif PPN tidak begitu berpengaruh terhadap konsumsi dan pertumbuhan ekonomi.

b. Kemudian berkaitan dengan rasio utang Jepang yang menjadi alasan pemerintah Jepang menaikkan tarif PPN juga tidak terdampak signifikan. Rasio utang Jepang justru terus bertambah selama 15 tahun terakhir bahkan menembus angka $266.2 \%$ pada tahun 2020.

c. Kenaikan tarif PPN meningkatkan inflasi di Jepang, sebenarnya hal ini bagus bagi Jepang yang puluhan tahun mengalami deflasi namun demikian berdampak negative pada pertumbuhan ekonomi.

Dari kesimpulan tersebut dapat diberikan saran kepada Pemerintah Indonesia, sebagai berikut:

1. Indonesia dapat mengalami pertumbuhan ekonomi yang positif dan juga menaikkan konsumsi dengan rencana kenaikan tarif PPN. Meskipun Jepang gagal dalam hal ini, namun kondisi Indonesia yang mengalami bonus demografi sangat berbeda dengan Jepang. Pemerintah harus melihat ini sebagai sebuah kesempatan dengan bertumbuhnya golongan menengah ke atas, tentunya konsumsi akan terus naik dan akan berakibat pada peningkatan perokonomian dengan adanya kenaikan tarif PPN.

2. Selanjutnya untuk mengatasi dampak buruk inflasi, pemerintah perlu untuk menyiapkan skema kebijakan pajak dan pengontrolan harga agar inflasi tetap dapat dikendalikan di tengah kenaikan tarif PPN yang akan mengakibatkan stimulasi kenaikan harga.

\section{IMPLIKASI DAN KETERBATASAN}

Tentunya tulisan ini sangat jauh dari kesempurnaan. Namun, harapan penulis agar dapat membawa manfaat bagi pembaca dan agar ke depan dapat dilanjutkan untuk melihat dampak kenaikan tarif PPN dari berbagai sisi tidak hanya dampak terhadap ppertumbuhan ekonomi dan tabungan nasional melainkan dari berbagai aspek makro dan 
mikro ekonomi. Serta dapat melakukan evaluasi setelah kebijakan ini berlaku.

\section{DAFTAR PUSTAKA (REFERENCES)}

Abd Hakim, T., Karia, A. A., \& Bujang, I. (2016). Does goods and services tax stimulate economic growth? International evidence. Journal of business and retail management research, 10(3).

Aini , J.H dan Setyari, N.P.W. (2019). Hubungan Kausalitas Tabungan Nasional dan Investasi Asing Langsung di Indonesia. E-journal Ekonomi Pembangunan Universitas Udayana. Vol.8 No.3 Maret 2019. 639-668.

Alm, J., \& El-Ganainy, A. (2013). Value-added taxation and consumption. International Tax and Public Finance, 20(1), 105-128.

Anojan, V. (2015). VALUE ADDED TAX (VAT), GROSS DOMESTIC PRODUCTION (GDP) AND BUDGET DEFICIT (BD): A CASE STUDY IN SRI LANKA. Department of Accounting, Faculty of Management Studies and Commerce, University of Jaffna, Sri Lanka.

Dahri, S. H. (2019). Pak-Japan comparative study of consumption tax (value added tax) and its effects on economic growth rate and gross savings.

Direktorat Penyusunan APBN. (2016). Buku Saku dan Indikator Ekonomi.DJA-Kemenkeu RI

Direktorat Jenderal Pajak. (2020). Buku Saku Pajak Dalam Angka.

Domar, E. D. (1946). Capital expansion, rate of growth, and employment. Econometrica, Journal of the Econometric Society, 137-147.

Ebrill, M. L. P., Keen, M. M., \& Perry, M. V. P. (2001). The modern VAT. International Monetary Fund.

Hong, Cesilia. (2019). HUBUNGAN INFLASI TERHADAP PERTUMBUHAN EKONOMI DI INDONESIA. Skripsi. Universitas Tarumanegara

Keen, M., Pradhan, M., Kang, K., \& de Mooij, R. (2011). Raising the Consumption Tax in Japan: Why, When, How?. Staff Discussion Notes, 2011(013).

Kementerian Keuangan Republik Indonesia. (2021). Undang-Undang Harmonisasi Peraturan Perpajakan. Membangun Sistem Perpajakan yang Adil, Sehat, Efektif dan Akuntabel. Dipaparkan pada siaran pers Oktober 2021.

Kementerian Keuangan Republik Indonesia. (2020). Anggaran Pendapatan dan Belanja Negara 2020.

Mankiw, N. G. (2007). Macroeconomics.

Maulida, Rani. (2018), UU PPN: Sejarah Pajak Pertambahan Nilai di Indonesia. www.pajakonline.com
Miki, B. (2011). The effect of the VAT rate change on aggregate consumption and economic growth. 2011. Columbia University

Mody, A., \& Ohnsorge, F. L. (2007). Can domestic policies influence inflation? (No. 2007/257). International Monetary Fund.

Rancangan Undang-Undang Harmonisasi Kebijakan. 2021.

Sthanumoorthy, R. (2006). Rate war, race to the bottom and uniform state VAT rates: An empirical foundation for a difficult policy issue. Economic and Political Weekly, 24602469.

Sukardji, U. (2009). SH: Pajak Pertambahan Nilai Edisi Revisi 2009. Jakarta: Rajawali Pers.

Tait, M. A. A. (1988). Value added tax: International practice and problems (Vol. 24). International Monetary Fund.

Wijaya, D. M. A. (2013). Pengaruh Pertumbuhan Ekonomi dan Tingkat Inflasi Regional terhadap PPN DN di Bali. E-Jurnal Akuntansi, 368-377.

https://www.globalvatcompliance.com/worldcountries-vat-rates-2020/diakses pada 30 oktober 2021

https://www.globalvatcompliance.com/worldcountries-vat-rates-2020/ pada 30 oktober 2021 


\section{LAMPIRAN}

\section{Hasil Output Regresi}

a. PPN Vs PDB

Variables Entered/Removed ${ }^{\text {b }}$

\begin{tabular}{|l|l|l|l|}
\hline Model & \multicolumn{1}{|c|}{$\begin{array}{c}\text { Variables } \\
\text { Entered }\end{array}$} & $\begin{array}{c}\text { Variables } \\
\text { Removed }\end{array}$ & Method \\
\hline 1 & Tax $^{\mathrm{a}}$ & & Enter \\
\hline
\end{tabular}

a. All requested variables entered.

b. Dependent Variable: GDP_gr

\begin{tabular}{|l|r|r|r|c|}
\multicolumn{1}{|c}{ Model Summary } \\
Model & $\mathrm{R}$ & R Square & $\begin{array}{c}\text { Adjusted R } \\
\text { Square }\end{array}$ & $\begin{array}{c}\text { Std. Error of the } \\
\text { Estimate }\end{array}$ \\
\hline 1 & $.992^{\mathrm{a}}$ & .984 & .983 & 599.37978 \\
\hline
\end{tabular}

a. Predictors: (Constant), Tax

ANOVA $^{b}$

\begin{tabular}{|ll|r|r|r|r|r|}
\hline \multicolumn{1}{|l|}{ Model } & & Sum of Squares & df & Mean Square & \multicolumn{1}{c|}{$\mathrm{F}$} & \multicolumn{1}{c|}{ Sig. } \\
\hline 1 & Regression & $3.614 \mathrm{E} 8$ & 1 & $3.614 \mathrm{E} 8$ & 1006.039 & $.000^{\mathrm{a}}$ \\
& Residual & 5748097.975 & 16 & 359256.123 & & \\
& Total & $3.672 \mathrm{E} 8$ & 17 & & & \\
\hline
\end{tabular}

a. Predictors: (Constant), Tax

b. Dependent Variable: GDP_gr

\begin{tabular}{|c|c|c|c|c|c|c|}
\hline \multicolumn{7}{|c|}{ Coefficients $^{a}$} \\
\hline \multirow{2}{*}{\multicolumn{2}{|c|}{ Model }} & \multicolumn{2}{|c|}{ Unstandardized Coefficients } & $\begin{array}{c}\text { Standardized } \\
\text { Coefficients }\end{array}$ & \multirow[b]{2}{*}{$\mathrm{t}$} & \multirow[b]{2}{*}{ Sig. } \\
\hline & & B & Std. Error & Beta & & \\
\hline 1 & (Constant) & -310.117 & 289.027 & & -1.073 & .299 \\
\hline & $\operatorname{Tax}$ & 28.500 & .899 & .992 & 31.718 & .000 \\
\hline
\end{tabular}

a. Dependent Variable: GDP_gr 
b. PPN Vs Tabungan Nasional

Variables Entered/Removed ${ }^{\text {b }}$

\begin{tabular}{|l|l|l|l|}
\hline Model & \multicolumn{1}{|l|}{$\begin{array}{c}\text { Variables } \\
\text { Entered }\end{array}$} & $\begin{array}{c}\text { Variables } \\
\text { Removed }\end{array}$ & \multicolumn{1}{|c|}{ Method } \\
\hline 1 & Tax $^{\mathrm{a}}$ & & Enter \\
\hline
\end{tabular}

a. All requested variables entered.

b. Dependent Variable: Gr_Saving

\section{Model Summary}

\begin{tabular}{|l|r|r|r|c|}
\hline Model & $\mathrm{R}$ & $\mathrm{R}$ Square & \multicolumn{1}{c|}{$\begin{array}{c}\text { Adjusted R } \\
\text { Square }\end{array}$} & $\begin{array}{c}\text { Std. Error of the } \\
\text { Estimate }\end{array}$ \\
\hline 1 & $.991^{\mathrm{a}}$ & .982 & .981 & 209.26733 \\
\hline
\end{tabular}

a. Predictors: (Constant), Tax

ANOVA $^{b}$

\begin{tabular}{|c|c|c|c|c|c|c|}
\hline \multicolumn{2}{|c|}{ Model } & Sum of Squares & df & Mean Square & $\mathrm{F}$ & Sig. \\
\hline \multirow[t]{3}{*}{1} & Regression & 38454314.600 & 1 & 38454314.600 & 878.096 & $.000^{\mathrm{a}}$ \\
\hline & Residual & 700685.016 & 16 & 43792.814 & & \\
\hline & Total & 39154999.616 & 17 & & & \\
\hline
\end{tabular}

a. Predictors: (Constant), Tax

b. Dependent Variable: Gr_Saving

Coefficients $^{a}$

\begin{tabular}{|c|c|c|c|c|c|c|}
\hline \multirow{2}{*}{\multicolumn{2}{|c|}{ Model }} & \multicolumn{2}{|c|}{ Unstandardized Coefficients } & \multirow{2}{*}{$\begin{array}{c}\text { Standardized } \\
\text { Coefficients } \\
\text { Beta }\end{array}$} & \multirow[b]{2}{*}{$\mathrm{t}$} & \multirow[b]{2}{*}{ Sig. } \\
\hline & & $\mathrm{B}$ & Std. Error & & & \\
\hline \multirow[t]{2}{*}{1} & (Constant) & -293.593 & 100.911 & & -2.909 & .010 \\
\hline & Tax & 9.296 & .314 & .991 & 29.633 & .000 \\
\hline
\end{tabular}

a. Dependent Variable: Gr_Saving 


\section{Tarif PPN di negara lain}

Tabel 3. Tarif PPN di Negara-Negara Lain

\begin{tabular}{|c|c|c|c|c|c|}
\hline No & Nama Negara & Tarif PPN & No & Nama Negara & Tarif PPN \\
\hline 1 & Algeria & $19 \%$. & 38 & Iraq & - \\
\hline 2 & Andorra & $4.5 \%$ s.d $9.5 \%$ & 39 & Isle of Man & $20 \%$ \\
\hline 3 & Argentina & $21 \%$ & 40 & Israel & $17 \%$ \\
\hline 4 & Armenia & $20 \%$. & 41 & Japan & $10 \%$ \\
\hline 5 & Australia & $10 \%$. & 42 & Jersey & $5 \%$ \\
\hline 6 & Azerbaijan & $18 \%$. & 43 & Kazakhstan & $12 \%$ \\
\hline 7 & Bahamas & $12 \%$ & 44 & Korea & $10 \%$ \\
\hline 8 & Bahrain & $5 \%$. & 45 & Kuwait & - \\
\hline 9 & Bangladesh & $15 \%$. & 46 & Malaysia & $10 \%$ plus $6 \%$ \\
\hline 10 & Barbados & $17.50 \%$ & 47 & Mauritius & $15 \%$ \\
\hline 11 & Belize & $12.50 \%$ & 48 & Mexico & 165 \\
\hline 12 & Bolivia & $14.94 \%$. & 49 & Morocco & $20 \%$ \\
\hline 13 & Botswana & $14 \%$ & 50 & New Zealand & $15 \%$ \\
\hline 14 & Brazil & $17 \%$ s.d $25 \%$ & 51 & Nigeria & $7.50 \%$ \\
\hline 15 & Bulgaria & $20 \%$ & 52 & Oman & $5 \%$ \\
\hline 16 & Canada & $5 \%$ & 53 & Pakistan & $17 \%$ \\
\hline 17 & Cayman Islands & - & 54 & Panama & $7 \%$ \\
\hline 18 & Chile & $19 \%$ & 55 & Peru & $18 \%$ \\
\hline 19 & China & $13 \%$ & 56 & Philippines & $12 \%$ \\
\hline 20 & Colombia & $19 \%$ & 57 & Puerto Rico & $11.50 \%$ \\
\hline 21 & Cook Islands & $15 \%$ & 58 & Qatar & - \\
\hline 22 & Costa Rica & $13 \%$ & 59 & Russia & $20 \%$ \\
\hline 23 & Curaçao & - & 60 & Saudi Arabia & $15 \%$ \\
\hline 24 & Dubai & $5 \%$ & 61 & Singapore & $7 \%$ \\
\hline 25 & Ecuador & $12 \%$ & 62 & Taiwan & $5 \%$ \\
\hline 26 & Egypt & $14 \%$ & 63 & Thailand & $6.30 \%$ \\
\hline 27 & El Salvador & $13 \%$ & 64 & Tunisia & $19 \%$ \\
\hline 28 & Equatorial Guinea & $15 \%$ & 65 & Turkey & $18 \%$ \\
\hline 29 & Ethiopia & $15 \%$ & 66 & Turks and Caicos & - \\
\hline 30 & Faroe Islands & $25 \%$ & 67 & Ukraine & $20 \%$ \\
\hline 31 & Georgia & $18 \%$ & 68 & United Kingdom & $20 \%$ \\
\hline 32 & Gibraltar & - & 69 & Uruguay & $22 \%$ \\
\hline 33 & Guatemala & $12 \%$ & 70 & USA & - \\
\hline 34 & Guernsey & - & 71 & Uzbekistan & $15 \%$ \\
\hline 35 & Hong Kong & - & 72 & Vanuatu & $15 \%$ \\
\hline 36 & India & $12 \%$ dan $18 \%$ & 73 & Venezuela & $16 \%$ \\
\hline 37 & Indonesia & $10 \%$ & 74 & Vietnam & $10 \%$ \\
\hline
\end{tabular}

Sumber: https://www.globalvatcompliance.com/world-countries-vat-rates-2020/ 


\section{Data Rasio Utang terhadap PDB (1990-2020) Indonesia Vs Jepang}

Gambar 1. Grafik Rasio Utang Terhadap PDB Jepang dan Indonesia Tahun 1990 s.d 2020 (dalam persen)

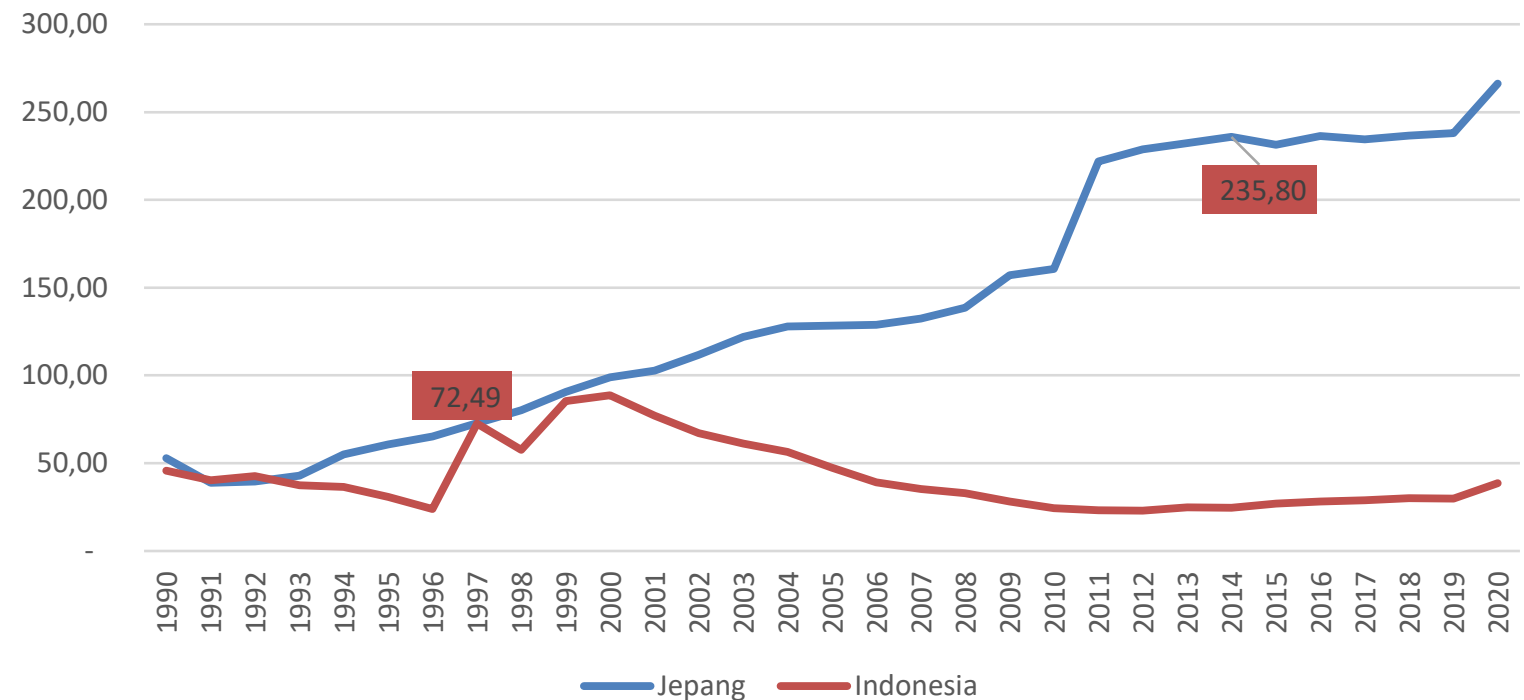

Sumber: Data World Bank, IMF, Kemenkeu Jepang dan Kemenkeu RI (diolah)

\section{Data Inflasi (1990-2020) Indonesia Vs Jepang}

Gambar 2. Grafik Pertumbuhan Ekonomi Jepang dan Indonesia Tahun 1990 s.d 2020 (dalam persen)

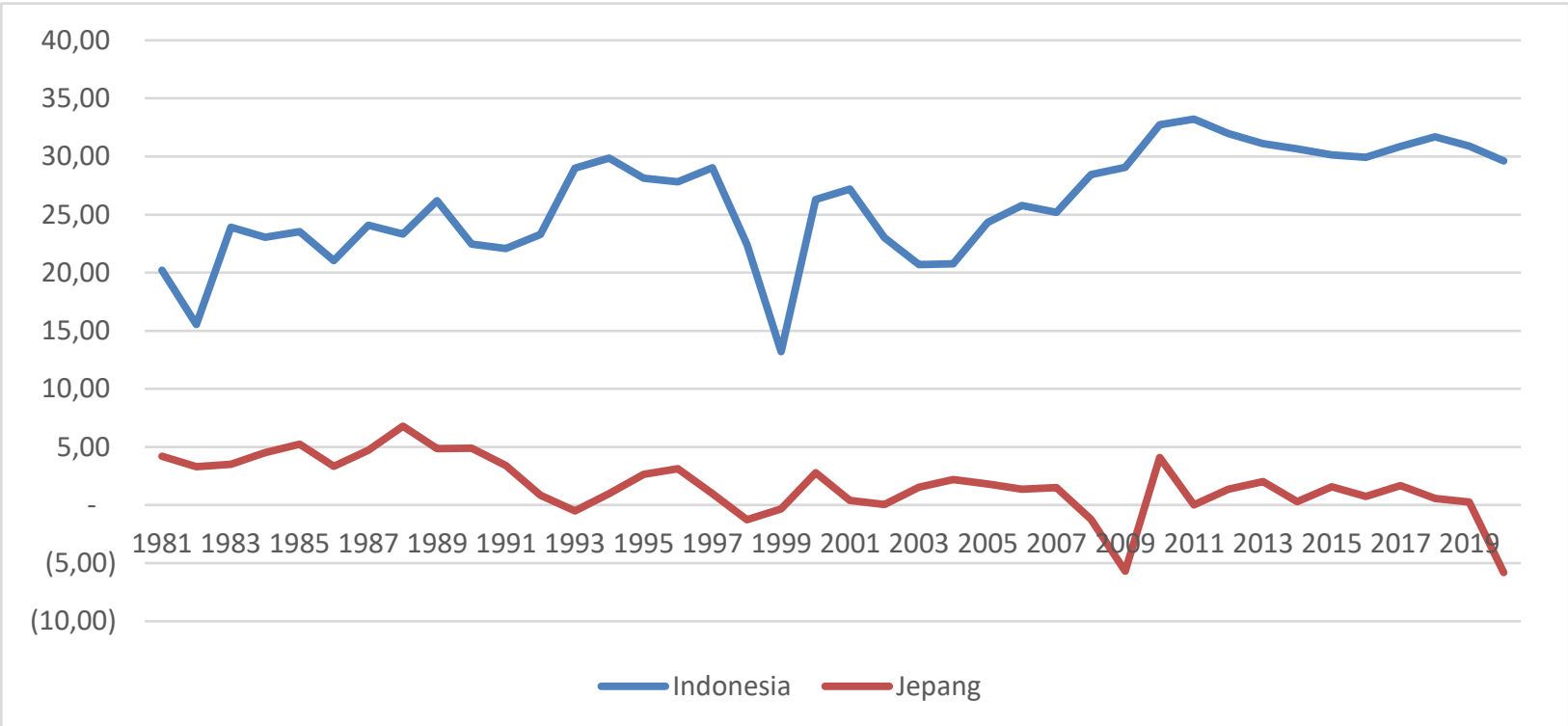

Sumber: Data World Bank, IMF, Kemenkeu Jepang dan Kemenkeu RI (diolah) 


\section{Data Belanja Pemerintah Indonesia}

\section{Gambar 3. Belanja Pemerintah Indonesia}

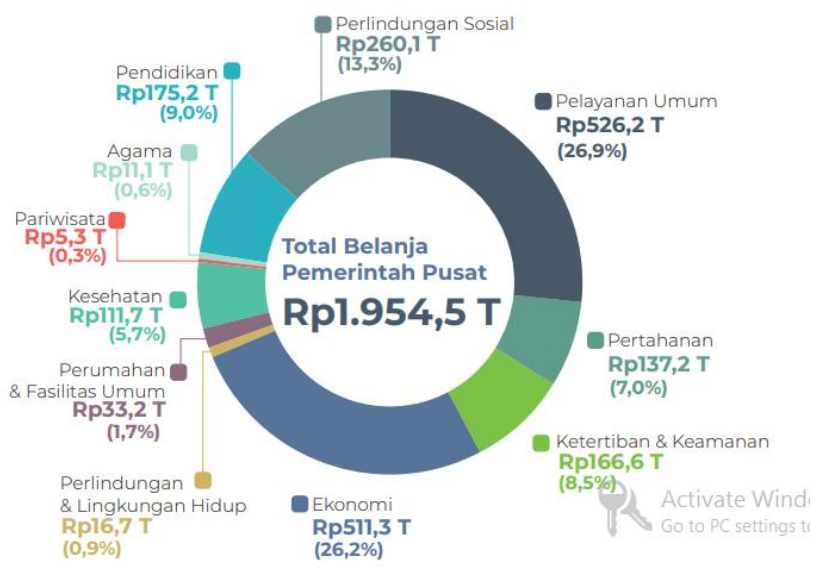

Sumber: informasi APBN 2021

6. Data Inflasi Pemerintah Jepang

Gambar 4. Grafik Inflasi Jepang (1970 s.d 2020)

\section{Inflasi Jepang (\%yoy)}

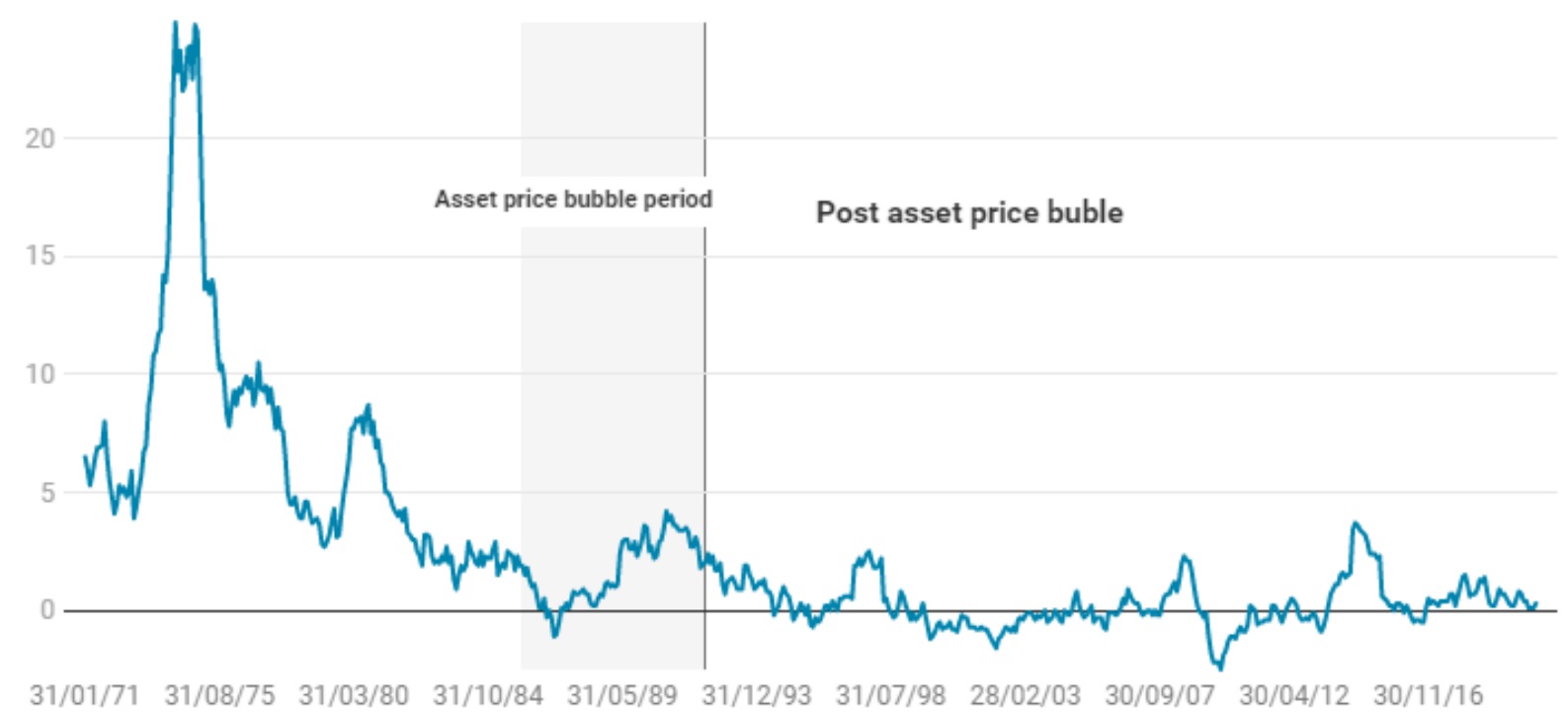

Sumber: Kemenkeu Jepang 